\title{
Strengthening of the hydrological cycle in future scenarios: atmospheric energy and water balance perspective
}

\author{
A. Alessandri ${ }^{1,6}$, P. G. Fogli ${ }^{2}$, M. Vichi ${ }^{2,5}$, and N. Zeng ${ }^{3,4}$ \\ ${ }^{1}$ Agenzia Nazionale Per le Nuove Tecnologie, L'Energia e lo Sviluppo Economico Sostenibile (ENEA), Rome, Italy \\ ${ }^{2}$ Centro Euro-Mediterraneo sui Cambiamenti Climatici, Bologna, Italy \\ ${ }^{3}$ University of Maryland, Department of Atmospheric and Oceanic Science, College Park, MD, USA \\ ${ }^{4}$ Earth System Science Interdisciplinary Center, College Park, MD, USA \\ ${ }^{5}$ Istituto Nazionale di Geofisica e Vulcanologia, Bologna, Italy \\ ${ }^{6}$ International Pacific Research Center, University of Hawaii at Manoa, Honolulu, HI, USA
}

Correspondence to: A. Alessandri (andrea.alessandri@enea.it)

Received: 27 June 2012 - Published in Earth Syst. Dynam. Discuss.: 12 July 2012

Revised: 7 October 2012 - Accepted: 16 October 2012 - Published: 22 November 2012

\begin{abstract}
Future climate scenarios experiencing global warming are expected to strengthen the hydrological cycle during the 21 st century (21C). We analyze the strengthening of the global-scale increase in precipitation from the perspective of changes in whole atmospheric water and energy balances. By combining energy and water equations for the whole atmosphere, we obtain constraints for the changes in surface fluxes and partitioning at the surface between sensible and latent components. We investigate the differences in the strengthening of the hydrological cycle in two centennial simulations performed with an Earth system model forced with specified atmospheric concentration pathways. Alongside the Special Report on Emissions Scenario (SRES) $\mathrm{A} 1 \mathrm{~B}$, which is a medium-high non-mitigation scenario, we consider a new aggressive-mitigation scenario (E1) with reduced fossil fuel use for energy production aimed at stabilizing global warming below $2 \mathrm{~K}$.

Our results show that the mitigation scenario effectively constrains the global warming with a stabilization below $2 \mathrm{~K}$ with respect to the 1950-2000 historical period. On the other hand, the E1 precipitation does not follow the temperature field toward a stabilization path but continues to increase over the mitigation period. Quite unexpectedly, the mitigation scenario is shown to strengthen the hydrological cycle even more than SRES A1B till around 2070. We show that this is mostly a consequence of the larger increase in the negative radiative imbalance of atmosphere in E1 compared to A1B. This appears to be primarily related to decreased
\end{abstract}

sulfate aerosol concentration in E1, which considerably reduces atmospheric absorption of solar radiation compared to A1B.

The last decades of the $21 \mathrm{C}$ show a marked increase in global precipitation in A1B compared to E1, despite the fact that the two scenarios display almost the same overall increase of radiative imbalance with respect to the 20th century. Our results show that radiative cooling is weakly effective in A1B throughout the 21C. Two distinct mechanisms characterize the diverse strengthening of the hydrological cycle in the middle and end- $21 \mathrm{C}$. It is only through a very large perturbation of surface fluxes that A1B achieves a larger increase in global precipitation in the last decades of the $21 \mathrm{C}$. Our energy/water budget analysis shows that this behavior is ultimately due to a bifurcation in the Bowen ratio change between the two scenarios.

This work warns that mitigation policies that promote aerosol abatement, may lead to an unexpected stronger intensification of the hydrological cycle and associated changes that may last for decades after global warming is effectively mitigated. On the other hand, it is also suggested that predictable components of the radiative forcing by aerosols may have the potential to effectively contribute to the decadalscale predictability of changes in the hydrological strength. 


\section{Introduction}

Future climate scenarios experiencing global warming are expected to somewhat strengthen the global-scale hydrological cycle during the 21st century (e.g. Huntington, 2006). The equilibrium precipitation sensitivity $(\Delta P)$ to temperature change $(\Delta T)$ has been estimated to be $\sim 2$ $3 \% \mathrm{~K}^{-1}$ (Held and Soden, 2006; Andrews et al., 2010). Because the non-equilibrium condition is what normally exists in the real world, precipitation change displays marked transient variability at the inter-decadal and longer time scales, which affects the projections of $\Delta P$ with a very large uncertainty (Johns et al., 2011; Douville et al., 2006; Feichter et al., 2004). Therefore, the relationship between the increase in temperature and precipitation is highly uncertain and cannot be assumed a priori (Trenberth and Shea, 2005; Trenberth et al., 2007; Lambert and Webb, 2008).

Precipitation changes are primarily constrained by the availability of precipitable water that follows from the atmospheric water balance equation (e.g. Hartman, 1994; Alessandri et al., 2007). On the other hand, including consideration of the atmospheric energy balance can further aid analysis of observed and projected precipitation changes (Andrews et al., 2009, 2010). Previous research has shown that precipitation also responds to the change in atmospheric radiative imbalance caused by the presence of forcing agents such as greenhouse gases (GHGs) and aerosols (e.g. Liepert et al., 2004; Andrews et al., 2010; Feichter et al., 2004). From the static stability point of view, the heating of the atmosphere by GHGs and the related water-vapor positive feedback leads to a more stable atmosphere, which may decrease convection and rainfall occurrence (Trenberth, 2011). That is, any perturbation to the atmospheric radiative cooling may compete or be balanced by a change in precipitation (Andrews et al., 2010). Previous studies have shown that hydrological sensitivity is larger for solar radiation forcing compared to GHG effects (e.g. Andrews et al., 2009). Therefore, absorption and reflection of solar radiation by aerosols are particularly effective in reducing global-scale precipitation (Trenberth, 2011; Wentz et al., 2007; Feichter et al., 2004). In this respect, Liepert and Previdi (2009) explicitly showed that the precipitation in coupled GCM can be more than three times more sensitive to aerosols compared to GHGs forcing. Furthermore, Liepert and Previdi (2009) applied a method to thermodynamically constrain global precipitation changes and showed that they are linearly related to the changes in the atmospheric radiative imbalance. The strength of this relationship is controlled by the ratio of the change in global surface sensible heat flux to the change in latent heat flux (Liepert and Previdi, 2009).

Recently, Johns et al. (2011) analyzed uncertainty in climate projections by comparing the Special Report on Emissions Scenario (SRES) A1B, a medium-high non-mitigation scenario (Nakicenovic and Swart, 2000), and a new aggressive mitigation scenario (E1) using a multi-model approach in the framework of the ENSEMBLES project (Johns et al., 2011). They showed a significantly lower global warming and precipitation increase for E1 in the late 21st century (21C) projection. They also revealed an unexpectedly robust response between the models involved in displaying greater strengthening of the hydrological cycle in E1 compared to A1B for the first part of the 21C. This behavior was suggested to be related to the mitigated forcing by aerosols in E1 (Johns et al., 2011).

In this study, we evaluate the effect of the E1 mitigation scenario on the strengthening of the hydrological cycle by comparison to the SRES A1B scenario. The strength of the hydrological cycle is measured by taking the spatial average of the precipitation rate in one of the Earth System Models (ESMs) participating to the ENSEMBLES centennial climate projection exercise (Johns et al., 2011). The reasons for the different precipitation changes during the E1 mitigation scenario compared to A1B are investigated by applying a method that is based on both water and energy conservation principles in the atmosphere. It is the first time that this kind of analysis is applied to a state-of-the-art ESM. The method is similar to the approach in Liepert and Previdi (2009) and the main difference is that it can also be applied to regional domains and not only to the global average. In Sect. 2, we discuss the method used and briefly describe the ESM and the scenario pathways used in Sects. 2.1 and 2.2, respectively. Section 2.3 defines the tool for analysis of precipitation changes based on water and energy balance equations. In Sect. 3, the results are reported and the constraints to precipitation changes coming from atmospheric water (Sect. 3.1) and atmospheric energy (Sect. 3.2) conservation equations are analyzed. Section 3.3 investigates the implications for the surface partitioning between sensible and latent heat fluxes. Finally, we summarize our findings and conclusions in Sect. 4.

\section{Method}

In this work the strength of the global-scale hydrological cycle is measured by the spatially-averaged rate of precipitation. The modeling data employed are simulations performed with the CMCC Earth System Model (C-ESM; see Sect. 2.1) following the protocol of the ENSEMBLES Stream 2 (ES2) multi-model experiment described in Johns et al. (2011) and briefly discussed in the following (see also Sect. 2.2). The ES2 experiment uses the new experimental design that has been proposed for the 5th IPCC assessment, which starts from benchmark concentration scenarios and aims to estimate the allowable anthropogenic emissions (Hibbard et al., 2007; Johns et al., 2011). It is important to note that in the ES2 simulations, the land and ocean feedbacks do not affect the atmospheric concentrations of GHGs, aerosols and other atmospheric pollutants. In fact, the ESMs are driven by GHG and air pollution concentration forcings derived from 
runs of Impact Assessment Models (IAMs). On the other hand, ESMs produce time series of diagnostic fluxes from the land-atmosphere and ocean-atmosphere components that are consistent with the increasing concentrations and the consequent modeled climate. In this sense, the ESMs record the implied (or allowable) anthropogenic carbon emissions as a direct output of the experiment by subtracting from the specified atmospheric $\mathrm{CO}_{2}$ growth rate the diagnosed natural carbon fluxes from the model. The analysis and the comparison of the implied emissions from the ESMs involved in the ES2 was the main aim of Johns et al. (2011), while details of the implied fluxes for the C-ESM are provided by Vichi et al. (2011).

\subsection{Model}

The C-ESM consists of an atmosphere-ocean-sea ice physical core coupled to land and ocean carbon cycle components. The technical description of the atmosphere-ocean coupling as well as the closure of the carbon cycle are described in Fogli et al. (2009), while the evaluation of the model in terms of global and regional ocean carbon uptake and related sensitivity to climate change is reported in Vichi et al. (2011). The model components are Océan PArallélisé version 8.2 (OPA8.2; Madec et al., 1998) for the ocean; ECmwf HAMburg version 5 (ECHAM5; Roeckner et al., 2003) for the atmosphere; the Louvain-la-Neuve sea ice model (LIM2; Timmermann et al., 2005); the PELAgic biogeochemistry for Global Ocean Simulations (PELAGOS) model for ocean biogeochemistry (Vichi et al., 2007a,b); and the Surface Interactive Land VegetAtion (SILVA; see description in following next paragraphs) model for the land-surface vegetation component. The external coupler OASIS3 (Valcke, 2006) is used to facilitate the exchanges for all relevant fields between the atmosphere and ocean components.

When considering atmospheric energy and water budgets it is of particular importance that the CGCM satisfy the basic conservation principles. As discussed in details in Fogli et al. (2009), the C-ESM model has been carefully checked for energy and water conservation and to this aim it implements on-line procedures aimed at ensuring conservation of the exchanged fluxes at the interface between surface and atmosphere. Recent studies have shown that some models have deficiencies in conserving energy and water at the interface between surface and atmosphere (Lucarini et al., 2008; Lucarini and Ragone, 2011; Liepert and Previdi, 2012). In particular, Lucarini et al. (2008) showed that imperfect closure of the energy cycle may lead to severe inconsistencies in some land models. As explained in Polcher et al. (1998) and Alessandri et al. (2007), these land models use semi-implicit or explicit coupling numerical scheme at the interface between surface and atmosphere, which does not ensure conservation of fluxes. This is due to the fact that within these schemes the solution of the surface energy balance equation by the land is done after the vertical diffusion parameterization is performed through the boundary layer. To obtain flux conservation at the interface, in the C-ESM model the coupling between SILVA and ECHAM5 is achieved by means of a fully implicit coupling numerical scheme for the energy and water fluxes. This scheme has been implemented with a flux conserving Neumann closure of the atmospheric vertical diffusion at the surface (Polcher et al., 1998; Alessandri et al., 2007), which allows for the simultaneous solution of both the surface balance equations and the closure of the turbulent fluxes in the boundary layer (Polcher et al., 1998; Alessandri, 2006; Alessandri et al., 2007). As discussed in Fogli et al. (2009), the conservation of energy exchanged between the atmosphere and the ocean is ensured by virtue of a two steps procedure: first the global integrals of the fluxes over the open water domain of the atmospheric model are computed. Thereafter, the global integrals seen by the atmospheric model are used to eventually correct the fluxes received by OPA8.2. A similar procedure is applied in order to obtain water conservation over Ocean. However, it is noted here that in the present version of the model, the water cycle between land and ocean is not closed, because the river-routing scheme is not implemented in the current version of the atmospheric model. Therefore, the conservation of the water mass is imposed after including a climatological river runoff (Fogli et al., 2009).

In the following we briefly summarize the characteristics of the SILVA model, which was only partially documented to the community through a previous scientific peerreviewed paper (Alessandri et al., 2007). The other components of the C-ESM were already extensively discussed in a companion paper by Vichi et al. (2011), which on the other hand cross-refers to this paper for the description of the land surface. The SILVA model parameterize the flux exchanges at the interface between land surface and atmosphere as described in Alessandri et al. (2007) and following the SECHIBA ("Schématisation des Echanges Hydriques á l'Interface entre la Biosphére et l'Atmosphére", Ducoudré et al., 1993) scheme approach, while the Vegetation and Carbon dynamics is developed using the core parameterizations from VEgetation-Global-Atmosphere-Soil (VEGAS, Zeng et al., 2005). SILVA can fully integrate the vegetationcarbon dynamics mechanistically with the characteristics of four plant functional types (PFTs): broadleaf tree; needleleaf tree; cold grass; and warm grass; with the different photosynthetic pathways distinguished for C3 (the first three PFTs above) and $\mathrm{C} 4$ (warm grass) plants. Competition between $\mathrm{C} 3$ and $\mathrm{C} 4$ grass is a function of temperature and $\mathrm{CO}_{2}$ following Collatz et al. (1998). Phenology is simulated dynamically as the balance between growth and respiration/turnover. Competition is determined by climatic constraints and resource allocation strategies such as temperature tolerance and height dependent shading of each PFT. The terrestrial carbon cycle starts with photosynthetic carbon assimilation in the leaves and the allocation of this carbon into three vegetation carbon pools: leaf, root and wood. After accounting 
for respiration, the biomass turnover from these three vegetation carbon pools cascades into a fast soil carbon pool, intermediate pool and a slow pool. Temperature and moisture dependent decomposition of these pools returns carbon back into atmosphere, thus closing the terrestrial carbon cycle. A natural fire module includes the effects of moisture availability, fuel loading, and PFT dependent resistance to combustion. As already discussed, the ES2 experiments do not allow the land and ocean feedbacks to the carbon cycle (Johns et al., 2011) so that, in the simulations analyzed in this study, the land carbon fluxes do not affect the atmospheric concentrations of GHGs and other atmospheric pollutants.

\subsection{Scenario pathways}

The scenario simulations performed with the C-ESM are those used for the ENSEMBLES Stream 2 (ES2) experimental framework and described in Johns et al. (2011). A historical (1860-1999) and two future scenario runs were performed by prescribing available pathways of well-mixed greenhouse gases (GHGs; Fig. 1) and sulfate aerosols (Fig. 2 reports total burden of sulfate aerosol) as boundary conditions. The GHGs $\left(\mathrm{CO}_{2}, \mathrm{CH}_{4}, \mathrm{~N}_{2} \mathrm{O}\right.$, and CFCs) and sulphate aerosols prescribed during the historical run are the observation-based concentrations available for the ENSEMBLES multi-model experiment (Johns et al., 2011, http://www.cnrm.meteo.fr/ensembles/public/ model_simulation.html). As described in Johns et al. (2011), for the 21st century forcing we used the GHG concentrations from the SRES A1B (Nakicenovic and Swart, 2000) and E1 scenarios. The E1 scenario was specifically developed for ENSEMBLES with the IMAGE2.4 Integrated Assessment Model (Bouwman et al., 2006; van Vuuren et al., 2007) as an aggressive mitigation scenario designed to keep anthropogenic warming below $2 \mathrm{~K}$. The aerosols boundary conditions consist of two components: one constant in time from the climatology developed in Tanre et al. (1984) (hereinafter Tanre climatology) plus time-dependent sulfate aerosols. The Tanre climatology distinguishes spatial distributions of sea, land, urban, and desert aerosols and contains constant background aerosols of tropospheric, stratospheric and volcanic type. The time varying 3-D concentration maps of sulfate aerosol for the historical, A1B and E1 scenarios were computed by running the chemistry-transport model (CTM Boucher and Pham, 2002), i.e. the same model used to evaluate the SRES scenario sulfate concentrations applied to the IPCC AR4 models (Johns et al., 2011). In this regard, we report that the indirect effect of aerosol on clouds implemented in Echam5 (i.e.: the atmospheric component of the C-ESM) distinguishes between maritime and continental clouds in the parameterization of precipitation formation, by considering the cloud droplet number concentration, in addition to the liquid water content (Lohmann and Roeckner, 1996). The cloud droplet number concentration is derived from the sulfate aerosol mass concentration

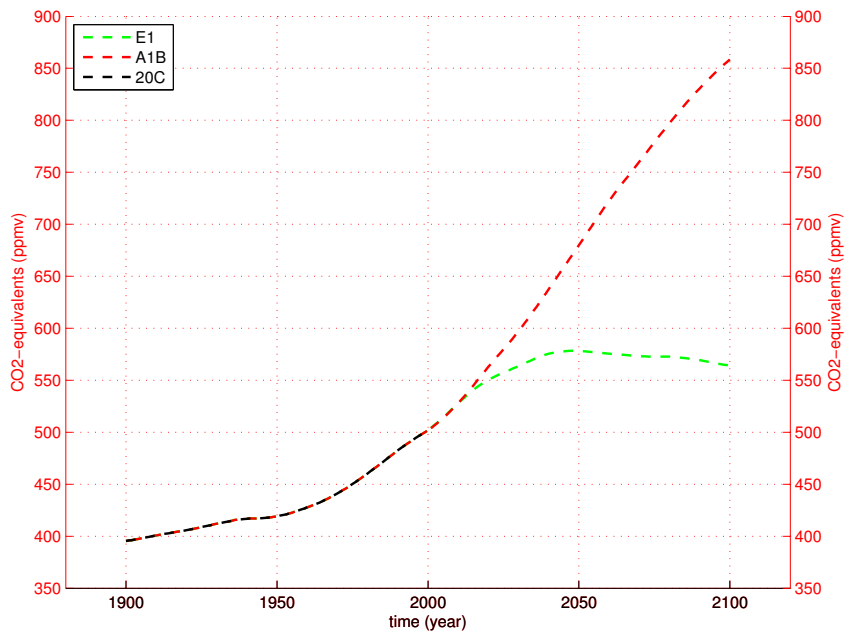

Fig. 1. Evolution of the prescribed greenhouse gases expressed as a concentration of $\mathrm{CO}_{2}$ equivalents (ppmv) for the historical observed period 1900-2000 (20C; black curve) and the two future scenarios. A1B (red) is the IPCC SRES marker scenario. E1 (green) is the mitigation scenario produced by the IMAGE integrated assessment model.

following Lohmann and Roeckner (1996). The C-ESM simulations were performed without any variation in natural forcing (solar, volcanic and fires). This means that natural aerosol burden does not change with increasing global warming. The ozone distribution from 1860 to 2100 is based on Kiehl et al. (1999), and includes the tropospheric ozone increase in the last decades, stratospheric ozone depletion and a simple projection for stratospheric ozone recovery applied to both A1B and E1 scenarios. For further details on scenario implementation and characteristics, refer to Johns et al. (2011).

\subsection{Atmospheric energy and water balance perspective to hydrological cycle acceleration}

The water vapor content in the atmosphere is a balance between the water fluxes at the lower boundary interface and horizontal moisture flux convergence so that the equation for the atmospheric water vapor content may be written as

$\frac{\partial W}{\partial t}=+E_{\uparrow}-\nabla_{h} \cdot \boldsymbol{Q}-P$

where $W$ is the amount of water vapor contained in a unit area atmospheric column, $E_{\uparrow}$ is the evapotranspiration, $P$ is the precipitation and $\boldsymbol{Q}$ is the vertically integrated (from the Earth's surface to the top of the atmosphere) horizontal transport vector of water vapor:

$$
\boldsymbol{Q}=\int_{\text {surface }}^{\text {top }} \boldsymbol{V} q \mathrm{~d} z
$$

where $\boldsymbol{V}$ is the horizontal wind vector, $q$ is atmospheric specific humidity, and $z$ is the height in meters. 


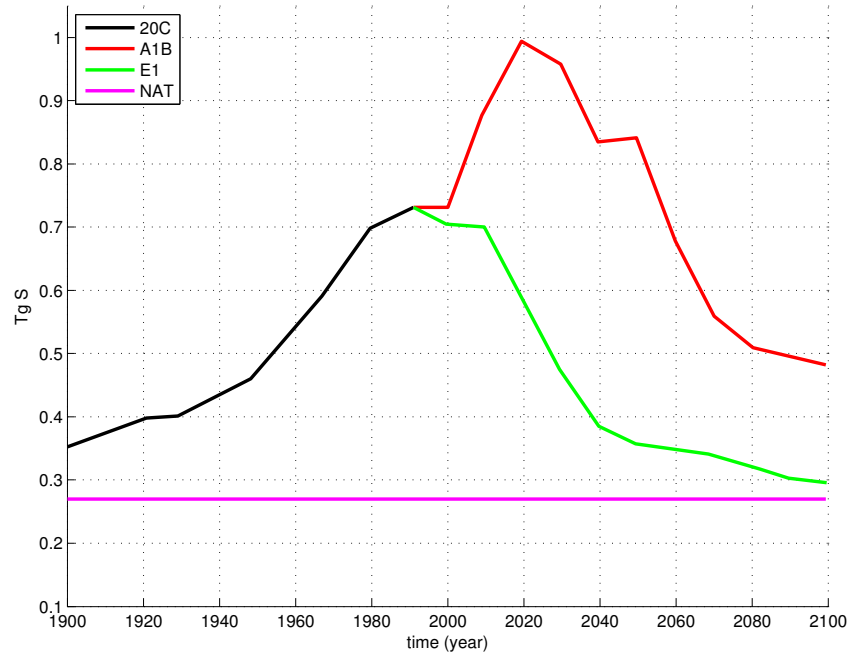

Fig. 2. Evolution of the prescribed total (anthropogenic + natural) sulfate aerosol burden ( $\mathrm{TgS}$ of total sulfate aerosol) for the observed historical period 1900-2000 (20C; black curve) and the two future scenarios. A1B (red) is the IPCC SRES marker scenario. E1 (green) is the mitigation scenario produced by the IMAGE integrated assessment model. Magenta line also reports constant natural contribution to sulfate aerosol burden.

Following Peixoto and Oort (1992), we can simplify the general balance equation after averaging time and space over a region bounded by a conceptual vertical wall and rearrange the equation to recognize contributions to precipitation as follows:

$$
\{\bar{P}\}=\left\{\overline{E_{\uparrow}}\right\}+\left\{-\overline{\nabla_{\mathrm{h}} \cdot \boldsymbol{Q}}\right\}-\left\{\frac{\overline{\partial W}}{\partial t}\right\}
$$

where the overbar indicates the time and the brackets stand for the space average, respectively. It is important to note that the tendency term is small and when considering the annual mean basis it can generally be neglected (e.g. Mariotti et al., 2001). A schematic diagram of the above atmospheric water balance is shown in Fig. 3a (rightmost box).

By evaluating the difference in the climatological annualmean precipitation between historical and future scenarios, as expressed in Eq. (3), we can effectively evaluate the contributions to the change in hydrological-cycle strength based on the atmospheric water conservation constraint as follows:

$\triangle\{\bar{P}\}=\triangle\left\{\overline{E_{\uparrow}}\right\}+\triangle\left\{-\overline{\nabla_{\mathrm{h}} \cdot \boldsymbol{Q}}\right\}$

where $\triangle$ indicates difference between projected scenario climate and historical climatology (Fig. 3b, right box).

Further constraint to the hydrological cycle comes from the principle of conservation of total potential energy which is defined as the sum of internal energy and gravitationalpotential energy. We are not considering kinetic energy here, since the related changes vanish when considering annualmean climatologies over a long period of time (Peixoto and
Oort, 1992). By computing the vertical integral, total potential energy represents the enthalpy content in the atmospheric column ( $H$; Peixoto and Oort, 1992):

$H=\int_{\text {surface }}^{\text {top }}(I+\phi) \mathrm{d} z=\int_{\text {surface }}^{\text {top }} \rho c_{p} T \mathrm{~d} z$

where $I$ is the internal energy and $\phi$ is the gravitationalpotential energy, $\rho$ is the density of air, $c_{p}$ is specific heat at constant pressure, and $T$ is temperature. The conservation principle states that changes in the atmospheric $H$ come from sensible heating $(\mathrm{SH})$, short wave $(S)$ radiative heating, long wave $(T)$ radiative heating and latent heating $(\mathrm{LP})$ :

$\frac{\partial H}{\partial t}=\mathrm{LP}+S_{\text {net }}+T_{\text {net }}+\mathrm{SH}$

where $S_{\text {net }}$ and $T_{\text {net }}$ corresponds to top of troposphere minus surface downward radiative-fluxes for $S$ and $T$, respectively; the term $\mathrm{SH}$ stands for atmospheric column sensible heating and as reported in Eq. (7) it can be further decomposed into two components: one is the turbulent flux of sensible heat at the surface $\left(\mathrm{SH}_{\uparrow}\right)$ that take place at very small spatial scales. On the other hand, the convergence term from atmospheric horizontal transport $\left(-\nabla_{\mathrm{h}} \cdot \boldsymbol{S} \boldsymbol{H}\right)$ is characterized by the large-scale dynamics.

$\mathrm{SH}=\mathrm{SH}_{\uparrow}-\nabla_{\mathrm{h}} \cdot \boldsymbol{S H}$

Here $\mathrm{SH}_{\uparrow}$ is the net balance between upward and downward flux components at the interface between surface an atmosphere and is here defined as positive-upward for convenience. In Eq. (6) we are considering the latent heat release during precipitation (LP) as an internal energy source so that we can write energy equation for the atmosphere in a different form (see Peixoto and Oort, 1992). Specifically, the budget here is applied to the enthalpy in the atmospheric column (vertical sum of total potential energy). As a consequence, atmospheric content of latent heat is not part of the budget and latent heat release during precipitation goes to the right hand side of the equation. On the other hand, from Eq. (3) and above discussion on water balance when considering annualmean basis, LP comes from the surface latent heat flux and the contribution from atmospheric convergence:

$\{L \bar{P}\}=\left\{L \overline{E_{\uparrow}}\right\}+\left\{-L \overline{\nabla_{\mathrm{h}} \cdot \boldsymbol{Q}}\right\}$

Note that $L \overline{E_{\uparrow}}$ is the net balance between upward and downward flux components at the interface between surface and atmosphere and is here defined as positive-upward for convenience.

Following the same approach applied to Eq. (1), we can simplify the energy balance equation after averaging in time and space and rearranging it to recognize regional precipitation contributions as follows:

$\{L \bar{P}\}=-\left\{\overline{S_{\text {net }}}\right\}-\left\{\overline{T_{\text {net }}}\right\}-\{\overline{\mathrm{SH}}\}+\left\{\overline{\frac{\partial H}{\partial t}}\right\}$. 
For annual-mean climatologies considered over a long period of time, we can assume the tendency term to vanish (e.g. Peixoto and Oort, 1992; Trenberth et al., 2001). It follows that, as shown in Fig. 3a (left boxes), the principle of the conservation of atmospheric energy requires that precipitation, and the related latent heating of the atmosphere, is balanced by radiative cooling and/or sensible heat loss. Similar to what was previously applied to the water balance equation, we can take the differences between scenario projections and historical simulations to quantify the contributions to projected changes in the strength of the hydrological cycle as follows:

$$
\begin{aligned}
\triangle\{L \bar{P}\}= & -\triangle\left\{-\overline{S_{\text {net }}}\right\}-\triangle\left\{-\overline{T_{\text {net }}}\right\} \\
& -\triangle\left\{\overline{\mathrm{SH}_{\uparrow}}\right\}-\triangle\left\{-\overline{\nabla_{\mathrm{h}} \cdot \boldsymbol{S H}}\right\} .
\end{aligned}
$$

As depicted in Fig. 3b (left box), Eq. (10) requires that any projected increase of precipitation must be balanced by a corresponding radiative cooling and/or a reduction in sensible heating. Note that our method is similar to the one in Liepert and Previdi (2009). However, the assumption that $P(\triangle P)$ must equal $E(\triangle E)$, i.e. at the base of their approach, applies only when considering global-mean annual climatology and it cannot be applied to regional domains. Differently, the method we propose is not limited to global means and so can be profitably applied to the analysis we further perform over global-land and global-ocean averages. However, our method is consistent with Liepert and Previdi (2009). In fact, it is easily shown that our Eq. (10) reduces to Eq. (4) in Liepert and Previdi (2009) when considering global mean averages.

By combining the equations for atmospheric water and energy balance (Eqs. 4 and 10), we can readily obtain important constraints on surface flux changes and partitioning at the surface between sensible and latent components. Specifically, equating the right hand side of Eq. (4) (multiplied by $L$ as in Eq. 8) and the right hand side of Eq. (10), the ratio between sensible and latent flux variations can be represented as

$$
\begin{aligned}
\frac{\Delta\left\{\overline{\mathrm{SH}_{\uparrow}}\right\}}{\Delta\left\{L \overline{E_{\uparrow}}\right\}}= & -\frac{\Delta\left\{-\overline{\left(S_{\text {net }}+T_{\text {net }}\right.}\right\}}{\Delta\left\{L \overline{E_{\uparrow}}\right\}}-\frac{\Delta\left\{-L \overline{\nabla_{h} \cdot \boldsymbol{Q}}\right\}}{\triangle\left\{L \overline{E_{\uparrow}}\right\}} \\
& -\frac{\Delta\left\{-\overline{\nabla_{\mathrm{h}} \cdot \boldsymbol{S H}}\right\}}{\Delta\left\{L \overline{E_{\uparrow}}\right\}}-1
\end{aligned}
$$

Note that our Eq. (11) reduces to Eq. (5) in Liepert and Previdi (2009) when considering global mean averages. Given the amount of precipitation change, Eq. (11) states the constraint on the surface partitioning that comes from changes in the atmospheric energy and water components. On the other hand, the ratio between the changes in the surface fluxes of sensible heat and latent heat (hereinafter Bowen ratio potential; $\mathrm{PBr}$ ) represents the potential to affect the Bowen ratio $(\mathrm{Br})$ at a given time. Assuming positive changes in latent heating from the surface, it is straightforward to show that $\mathrm{PBrs}$ that are larger (smaller) than current value of $\mathrm{Br}$ will a)

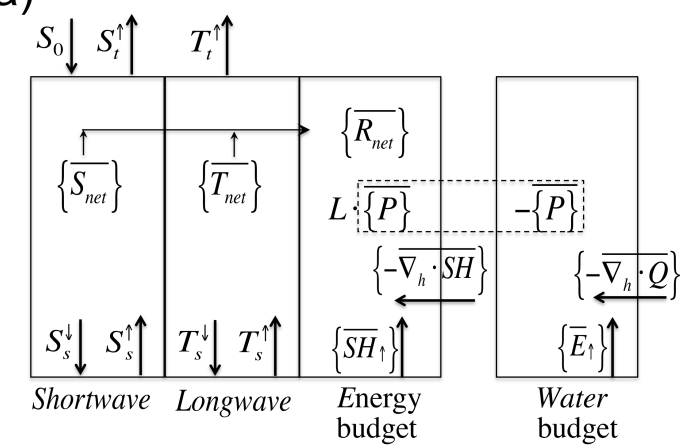

b)

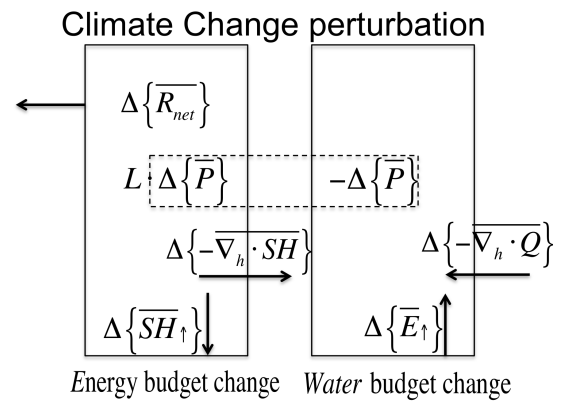

Fig. 3. Schematic diagram showing notation for the (a) the atmospheric energy and water budgets and (b) perturbation of atmospheric energy and water budgets following climate-change related precipitation increase. For both energy and water, the terms of the budgets (and budget changes) are displayed so that their sum equals zero following Eqs. (3), (4), (9) and (10). Rightmost boxes show the atmospheric water budget while the boxes on the left show the corresponding energy budgets. In (a) from left to right, the three boxes on the left show atmospheric shortwave, longwave and total energy budgets. $S$ and $T$ denote shortwave and longwave radiative fluxes, respectively, with arrows indicating upward or downward direction. Subscripts $s, t$ and $o$ stand for surface, top of the atmosphere and solar constant, respectively. $R_{\text {net }}$ is the net radiative flux as the sum of net longwave $\left(T_{\text {net }}\right)$ and shortwave $\left(S_{\text {net }}\right)$ components.

correspond to a positive (negative) change in $\mathrm{Br}$. It follows that $\mathrm{PBr}$ is the value to which $\mathrm{Br}$ will tend asymptotically, provided $\mathrm{PBr}$ is maintained constant long enough.

\section{Results}

The simulated climate shows a significantly lower warming response in $\mathrm{E} 1$ than in $\mathrm{A} 1 \mathrm{~B}$ in the late $21 \mathrm{C}$ projections (Fig. 4a), consistent with the GHGs concentration path (See also Fig. 1). On the other hand, the divergence in GHGs concentration pathways, with A1B increasingly exceeding E1, do not seem to dominate the temperature response in the first half of the century. In fact, the warming during the first half of the $21 \mathrm{C}$ in the E1 scenario often exceeds that in A1B. As documented in Johns et al. (2011), this is mostly due to the reduction in forcing by sulfate aerosols (Fig. 2) that led to considerably weakened aerosol cooling in E1 compared 
a)

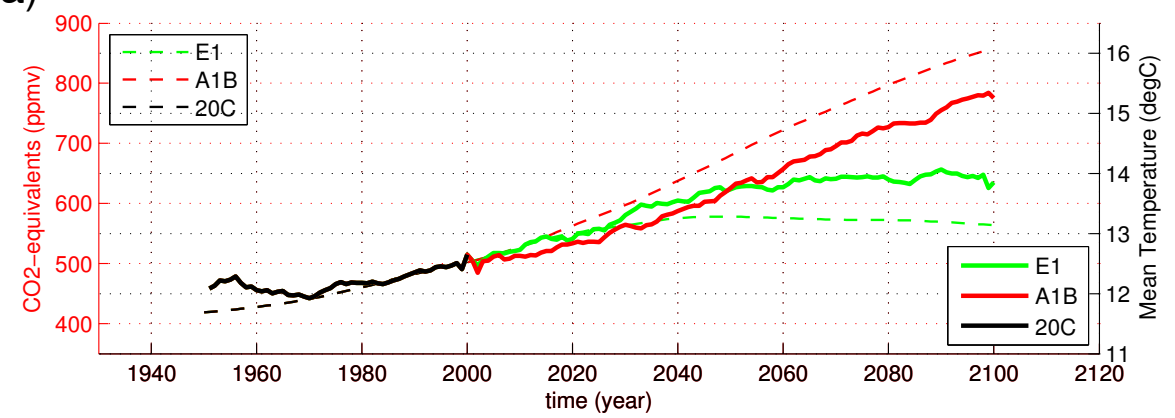

b)

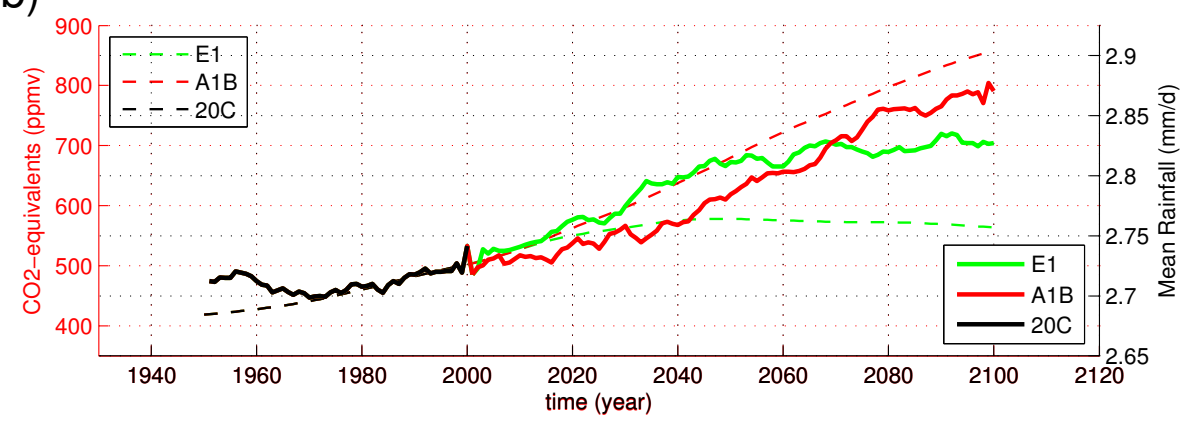

Fig. 4. Time evolution of 5-yr running means for globally-averaged (a) near surface temperature and (b) precipitation (right axis solid lines) vs. GHGs concentration (left axis dashed lines) for the observed historical period 1950-2000 (20C; black), A1B (red) and E1 (green).

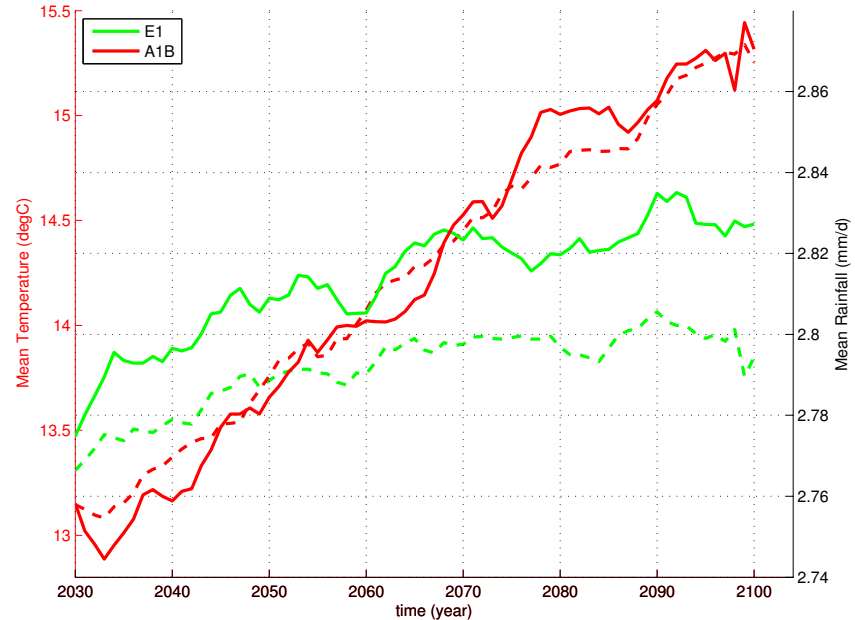

Fig. 5. 2030-2100 zoomed in time evolution of 5-yr running means for globally-averaged near surface temperature (left axis dashed lines) and precipitation (right axis solid lines) for the A1B (red) and E1 (green) scenarios.

to A1B. This behavior has been shown to be a robust response in all models involved in the same experimental exercise in the framework of the ENSEMBLES project (Johns et al., 2011). From Fig. 4 it is shown that E1 is effective in constraining global warning below $2 \mathrm{~K}$ compared to the 1950-2000 historical period. More importantly, it has accomplished a stationary solution of the cumulative warming, with the E1 temperature curve steadily achieving zero derivative during the last 4 decades of the $21 \mathrm{C}$. This is more clearly appreciated in Fig. 5, i.e. by zooming in on the 2030-2100 scenario time frame for both temperature and precipitation. On the contrary, the E1 precipitation does not follow the temperature field toward a stabilization path but continues to increase beyond 2070. It follows an uncoupled behavior of temperature and precipitation in E1, which leads to divergence in the respective curves. In this respect, A1B behaves very differently with the increases in both temperature and precipitation that appear tightly related and exhibit almost linear relation.

Figure $4 \mathrm{~b}$ shows that the global hydrological cycle unexpectedly strengthens more in E1 than in A1B well beyond the half of the $21 \mathrm{C}$, that is after that global temperature already intersected and with a much warmer A1B. In fact, global precipitation in E1 significantly exceeds that in A1B up until almost 2070 (Fig. 4b), thus showing that the relationship between precipitation and temperature changes is only part of the story and that there are other factors acting to weaken precipitation in A1B compared to E1. This is consistent with previous studies showing that precipitation also responds to the change in atmospheric radiative heating caused by the presence of the forcing agents such as GHGs and aerosols (Andrews et al., 2010). Feichter et al. (2004) showed that the relationship between precipitation and temperature is not necessarily positive and that in some cases global precipitation can even decrease in conjunction with global warming. 
a)

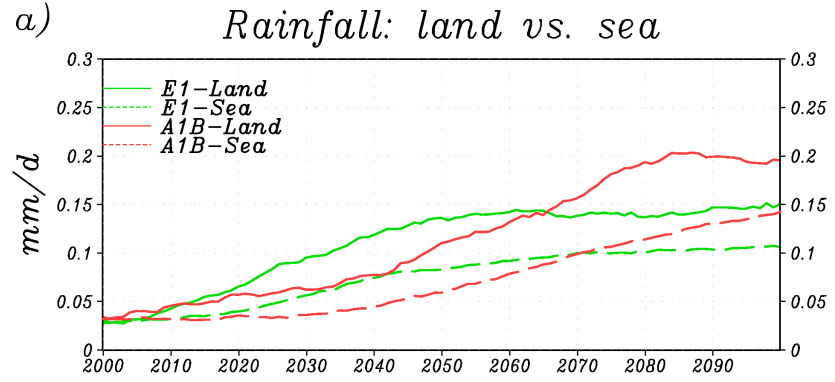

b)

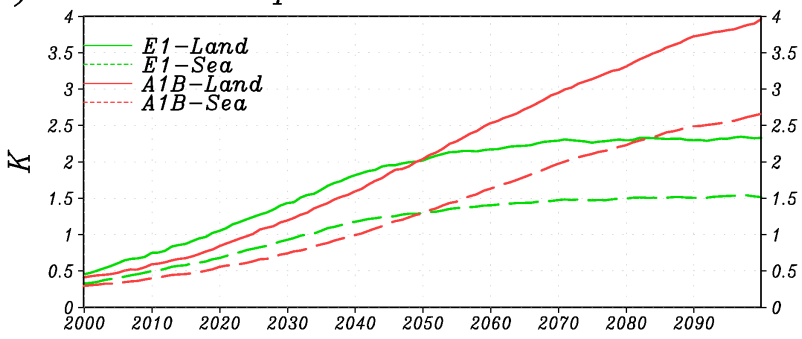

c)

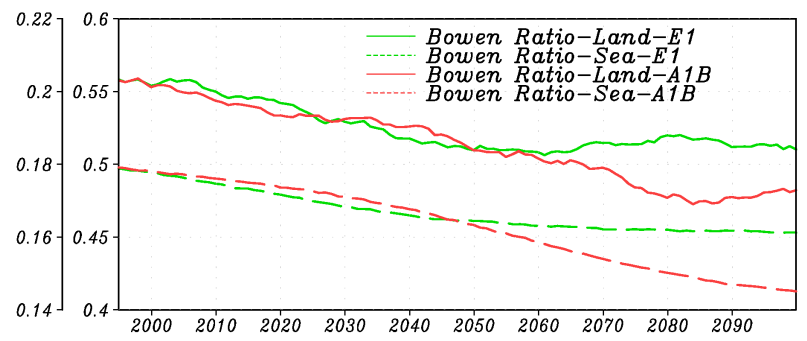

Fig. 6. Time evolution of 15 -yr running means for land averaged (solid lines) and sea averaged (dashed lines) change of (a) precipitation $\left(\mathrm{mm} \mathrm{d}^{-1}\right)$ and $(\mathbf{b})$ near surface temperature $(\mathrm{K})$ relative to 1970-2000 climatology. (c) The Br evolution with inner axis denoting land and the outer axis denoting ocean. A1B in red and E1 green.

Furthermore, the larger acceleration of the hydrological cycle in E1 could be consistent with previous findings that aerosolinduced forcing tends to exhibit a stronger hydrological response than GHG forcing (Liepert et al., 2004; Feichter et al., 2004; Andrews et al., 2009).

Figure 6 shows the scenario land vs. sea averaged changes in precipitation (panel a), temperature (panel b) and the Bowen ratio (Br; panel c). Consistent with previous studies (e.g. Sutton et al., 2007), it is shown that precipitation and temperature increase more over land than over ocean. However, for both E1 and A1B, the increases over land and over ocean appear in phase between each other indicating that, for each scenario, both warming and hydrology acceleration behave as global scale processes. Figure $6 \mathrm{c}$ shows that, as expected, the $\mathrm{Br}$ tends to decrease with the strengthening of the hydrological cycle over both land and oceans (Held and Soden, 2006). However, the comparison of the time evolution
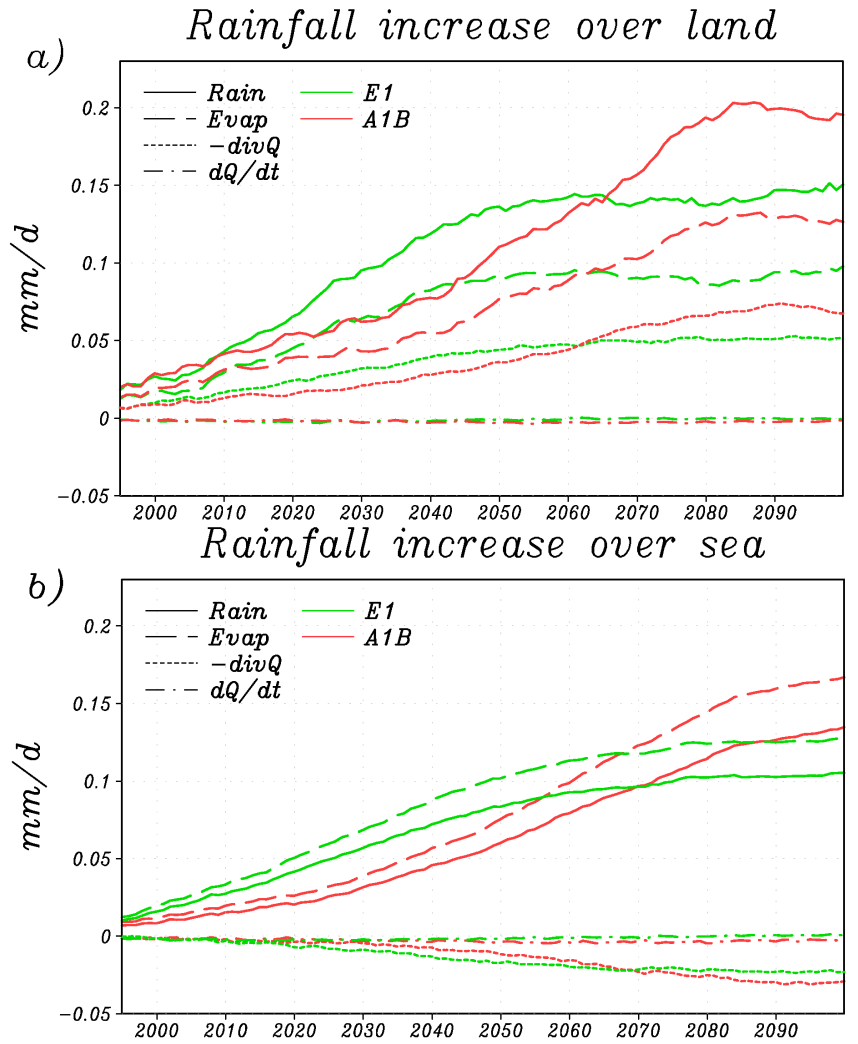

Fig. 7. Time evolution of 15-yr running means for (a) land averaged and (b) sea averaged contribution to rainfall change (solid lines) coming from local evapotranspiration (dashed lines), moisture convergence (dotted), and change in atmospheric total water content (dash-dot lines). A1B in red and E1 green.

between $\mathrm{E} 1$ and $\mathrm{A} 1 \mathrm{~B}$ shows that $\mathrm{Br}$ exhibits transient behavior that is different from precipitation. In fact, the $\mathrm{Br}$ for $\mathrm{E} 1$ and A1B are very similar until around 2060, over both land and sea, and it is only after 2060 (earlier over sea) and towards the end-21C that the divergence of $\mathrm{Br}$ between $\mathrm{A} 1 \mathrm{~B}$ and $\mathrm{E} 1$ occurs.

\subsection{Atmospheric water conservation constraints to the hydrological cycle}

In this section we analyze the difference between the projected and historical precipitation climatologies by exploiting Eq. (4), which was derived in Sect. 2. As summarized in Table 1, the precipitation increase at the end-21C, with respect to 1970-2000 climatology, amounts to 0.15$0.2 \mathrm{~mm} \mathrm{~d}^{-1}$ over global land (Fig. 7a) and $0.1-0.12 \mathrm{~mm} \mathrm{~d}^{-1}$ over global ocean (Fig. 7b). The acceleration of the hydrological cycle over global land during the $21 \mathrm{C}$ is mainly caused (for about two thirds) by the increased evapotranspiration over the continents (see Table 2, first column) and also (for about one third) by moisture convergence from the oceans (Table 2, third column) in both the E1 and A1B scenarios (Fig. 7a). This has implications for continental runoff, which 
Table 1. Change in (1st row) precipitation, (2nd row) temperature, (3rd row) Bowen ratio (Br) and (4th row) ratio of rainfall vs. temperature change for 2071-2100 and with respect to 1970-2000 climatology. Global land (ocean) averages in left (right) columns.

\begin{tabular}{lrrrr}
\hline & \multicolumn{2}{c}{ Global Land } & \multicolumn{2}{c}{ Global Ocean } \\
\cline { 2 - 5 } & \multicolumn{1}{c}{ E1 } & \multicolumn{1}{c}{ A1B } & \multicolumn{1}{c}{ E1 } & \multicolumn{1}{c}{ A1B } \\
\hline$\Delta$ Rain & 0.15 & 0.20 & 0.10 & 0.12 \\
$\Delta$ Temp & 2.3 & 3.8 & 1.5 & 2.5 \\
$\Delta$ Br & -0.05 & -0.11 & -0.02 & -0.03 \\
$\Delta$ Rain & 0.065 & 0.053 & 0.066 & 0.048 \\
$\Delta$ Temp & $(3.73 \% \mathrm{~K})$ & $(3.00 \% \mathrm{~K})$ & $(2.15 \% \mathrm{~K})$ & $(1.55 \% \mathrm{~K})$ \\
\hline
\end{tabular}

has to increase on average by the same amount as the change in water mass that is converged from the oceans, if the land water-storage does not change (Hartman, 1994). Indeed simulated water storage over global land is nearly constant during $21 \mathrm{C}$ in both E1 and A1B (not shown), thus implying that the increase in continental runoff is nearly the same as the amount of water converged through the atmosphere. In the mid-21C, precipitation increases more in E1 than in $\mathrm{A} 1 \mathrm{~B}$ over both land and sea, mostly because of the larger increase in surface evaporation. A considerable contribution over land (about one third) comes from the larger increase in moisture convergence from oceans compared to A1B (Table 2). On the other hand, enhanced moisture divergence over the ocean in E1 partially damps the precipitation increase there. A similar relative contribution from evaporation (about two thirds) and moisture convergence (about one third) is observed for the different precipitation change at the end of $21 \mathrm{C}$ (Table 2); in this case the precipitation increase is larger for A1B than for E1.

\subsection{Atmospheric energy conservation constraints to the hydrological cycle}

This section analyzes the contributions to the projected precipitation changes by applying the atmospheric energy conservation constraint and comparing it to the 1979-2000 reference climatology. For this purpose we use Eq. (10) (see Sect. 2), which states that change in the latent heating of the atmosphere due to rainfall increase (decrease) is possible provided that a change of the opposite sign occurs so that the atmosphere cools (warms) radiatively and/or that negative (positive) changes in sensible heating take place. The changes in the atmospheric net absorption of long-wave radiation are negative during the 21C E1 and A1B scenarios over both land and ocean (Fig. 8a). According to the StefanBoltzmann law, this appears consistent with increased thermal emission as a response to atmospheric warming (e.g. Trenberth, 2011). In fact, a comparison of Figs. 4a and $8 \mathrm{a}$ shows that the change in thermal radiation in the atmosphere, over both land and sea, closely follows the time progression of temperature. As a result, similar to air temperature
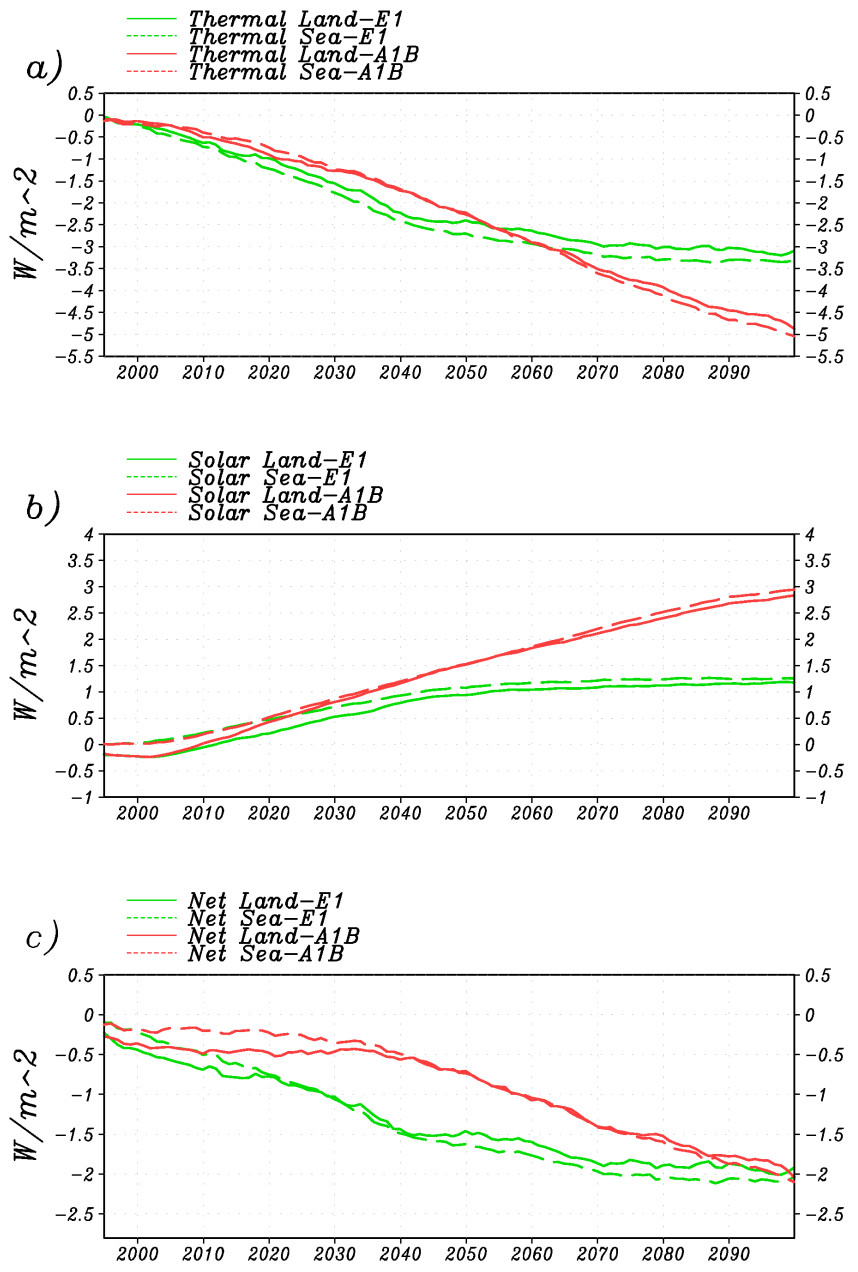

Fig. 8. Comparison of $15-\mathrm{yr}$ running means of the change in atmospheric vertical divergence for (a) thermal radiation, (b) solar radiation, and (c) net (solar + thermal) radiation with reference to 1970-2000 climatology. Land averages (solid lines) and sea averages (dashed lines) are reported for both A1B (red) and E1 (green) scenarios.

(Fig. 4a), the curves of thermal radiation changes for E1 and A1B intersect each other around 2050 (Fig. 8a; slightly later over sea than over land).

The atmospheric absorption of solar radiation (Fig. 8b) shows positive changes during the $21 \mathrm{C}$ mostly due to the effect of increased concentration of aerosols (Johns et al., 2011). However, baseline and mitigation scenarios diverge early in the $21 \mathrm{C}$, with the change in solar radiation in A1B exceeding that in $\mathrm{E} 1$ by more than $1.5 \mathrm{~W} \mathrm{~m}^{-2}$ at the end-21C (Fig. 8b). As previously discussed, this has been shown to be primarily due to the considerably abated aerosols in E1 compared to A1B (Johns et al., 2011).

Figure $8 \mathrm{c}$ reports the net (solar plus thermal) change in atmospheric radiation divergence, showing that radiative cooling during the $21 \mathrm{C}$ always acts to compensate at least in part the increase in latent heat release due to precipitation 
a)

Mid-21C (2035-2065) b)

End-21C (2099-2070)

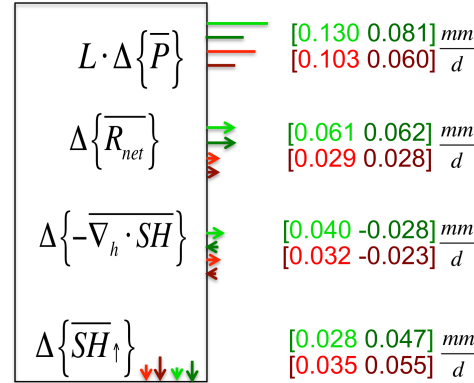

Energy budget change

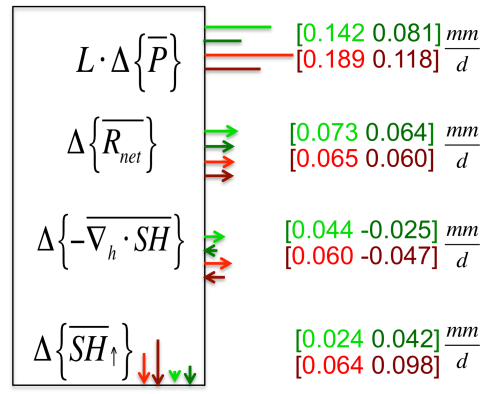

Energy budget change

Fig. 9. Schematization of the two distinct mechanisms characterizing the diverse strengthening of the hydrological cycle in (a) mid- and (b) end-21C. The atmospheric energy balance perturbation is the same as in Fig. 3b (left box) and colored numbers/arrows indicate precipitation change and the corresponding contributions to the energy balance coming from each term. Land averages (light colors) and sea averages (dark colors) are for A1B (red) and E1 (green).

enhancements. As summarized in Table 3 (columns 1-2), radiative cooling contributes considerably more in E1 than in A1B to the precipitation increase and also comparatively more over ocean than over land. Over sea (land), radiative cooling in E1 contributes $76.4 \%$ (47.0\%) and $78.3 \%$ $(52.7 \%)$ of the precipitation increase during mid- and end21C, respectively. In comparison, A1B displays a much smaller percentage of radiation contribution with only $48.1 \%$ in mid-21C and $50.9 \%$ in end-21C over ocean (see Table 3). Over land the radiative cooling contribution to precipitation changes are considerably smaller but display a substantial reduction in A1B (28.4\% in mid-21C and $34.0 \%$ in end-21C) compared to E1 (47.0\% in mid-21C and $52.7 \%$ in end-21C). It is important to note that, by considering radiation only, the precipitation increase in E1 should always exceed A1B. However, the change in precipitation in A1B became larger after 2070 (Fig. 6a), which implies that other factors come into play in the second half of the 21C. Figure 9 compares the contributions to precipitation for E1 and A1B in the mid21C climatology (2035-2065; panel a) and the end-21C climatology (2070-2100; panel b). In mid-21C the larger precipitation increase in E1 compared to A1B is supported, over both land and ocean, primarily by the reduced absorption of solar radiation and secondarily by increased thermal radiation loss (see Fig. 8). For the end-21C, the solar and thermal radiation balance each other (see Fig. 8) so that the net radiative contribution to the difference in precipitation increase is close to zero. Here, the much larger acceleration of the hydrological cycle in A1B compared to E1, over both land and ocean, is due to the marked divergence of the response in sensible heating towards the end- $21 \mathrm{C}$ (Fig. 9b). Figure 9b also shows that much of the difference in change comes from the modification of sensible heat flux from the surface, while only a small contribution is due to atmospheric sensible heat
Table 2. E1 vs. A1B contributions to rainfall change coming from surface evaporation (Evap) and atmospheric moisture convergence (Moist Conv) for (upper rows) 2035-2065 (mid.21C) and (lower rows) 2071-2100 (end-21C) with respect to 1970-2000 climatology. Global land (ocean) averages in left (right) columns for each contributing factor.

\begin{tabular}{cccccc}
\hline \multicolumn{4}{c}{$\begin{array}{c}\text { Contributions (\%) to Precipitation Change } \\
\text { from Atmospheric Water Conservation }\end{array}$} \\
\hline & & \multicolumn{2}{c}{ Evap } & \multicolumn{2}{c}{ Moist Conv } \\
\cline { 3 - 6 } Climatology & Scenario & Land & Sea & Land & Sea \\
\hline Mid-21C & E1 & 67.4 & 119.8 & 32.6 & -19.8 \\
$(2035-2065)$ & A1B & 65.8 & 123.9 & 34.2 & -23.9 \\
\hline End-21C & E1 & 63.8 & 121.6 & 36.2 & -21.6 \\
$(2070-2099)$ & A1B & 65.5 & 125.8 & 34.5 & -25.8 \\
\hline
\end{tabular}

convergence (see also Table 3). In summary, two distinct mechanisms characterizing the diverse strengthening of hydrological cycle in mid- and end-21C are clearly identified from Fig. 9. In mid-21C, it is the larger radiative cooling that determines higher precipitation for E1. On the other hand, the major reduction of surface sensible heat dominates the stronger A1B hydrology in end-21C.

\subsection{Implications for the surface sensible and latent flux}

The increase in precipitation is unavoidably coupled to the surface processes. As mentioned in Sect. 3.1, it has consequences for continental runoff, which is expected to increase by the same amount of the water mass that converges from the ocean through the atmosphere (except for changes in water mass storage over land). In this section we analyze the implications for the surface flux partitioning between sensible 

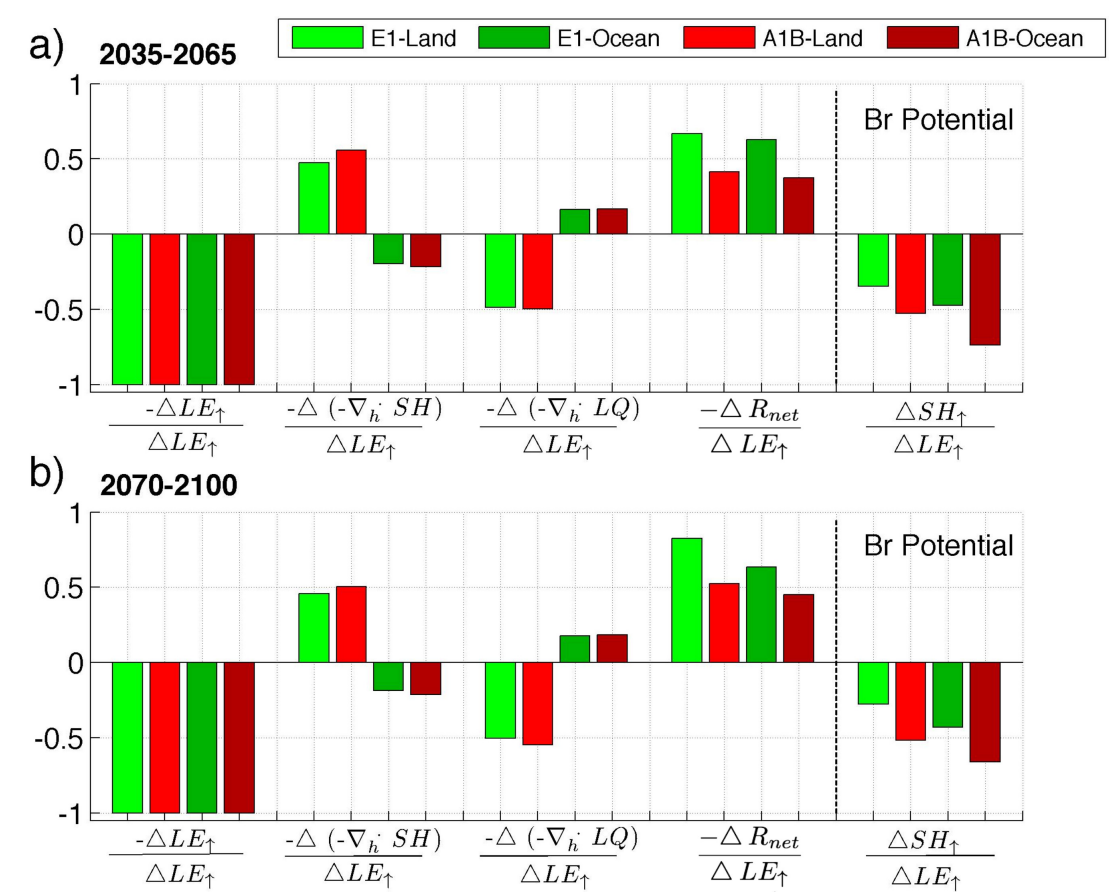

Fig. 10. Land averaged (light colors) and sea averaged (dark colors) contributions to the ratio between surface sensible and latent flux changes (Potential Bowen ratio; PBr), compared to the reference 1970-2000 climatology for (a) 2035-2065 and (b) 2070-2100 averages. Contributions from the atmospheric convergence of sensible heat $\left(-\nabla_{\mathrm{h}} \cdot \mathrm{SH}\right)$ and latent heat $\left(-\nabla_{\mathrm{h}} \cdot \mathrm{LQ}\right)$, radiation absorption $\left(R_{\mathrm{net}}\right)$ and surface latent heat $\left(\mathrm{LE}_{\uparrow}\right)$ are reported for $\mathrm{A} 1 \mathrm{~B}(\mathrm{red})$ and $\mathrm{E} 1$ (green).

and latent heat. Through Eq. (11), the PBr is defined as the ratio between change of surface fluxes of sensible and latent heat and is expressed as a function of the different contributing terms coming from the atmospheric water and energy equations. The results are reported in Fig. 10 for both the mid-21C (panel a) and the end-21C (panel b).

As previously mentioned, $\mathrm{Br}$ tends to decrease during the $21 \mathrm{C}$ for the E1 and A1B scenarios (Fig. 6c); this is supported by the negative $\mathrm{PBr}$ values shown in Fig. 10 . The -1.0 values of the first histogram-group on the left in Fig. 10 represent $\mathrm{PBrs}$ where surface sensible-heating reduction is the only factor compensating for the increased atmospheric energy coming from surface latent heat flux. For both E1 and A1B, there are other factors that compensate the input of latent heat from the surface. As shown in Fig. 10, the absolute value of $\mathrm{PBr}$ over land (ocean) is reduced (increased) by enhanced (decreased) divergence of sensible heat through the atmosphere. On the other hand, increased (reduced) atmospheric convergence of latent heat reduces (increases) the absolute value of $\mathrm{PBr}$ over land (ocean). However, in both mid-21C (Fig. 10a) and end-21C (Fig. 10b) and over both land and ocean, changes in sensible and latent heat convergence terms balance each other very closely so that they have no appreciable overall effect on PBr. Therefore, according to Eq. (11), the increased radiative cooling and reduced sensible heat flux (PBr) are the factors that dominate and compete in counterbalancing the increased evapotranspiration. For both land and ocean, the most important term for E1 acting to compensate the increased latent heat from the surface is the larger radiative cooling (Fig. 10). On the other hand, it is the $\mathrm{PBr}$ term (decrease of surface sensible heat) that dominates in A1B. The difference between E1 and A1B is highest in the end-21C and, in particular, over land (Fig. 10b) where the atmospheric net radiation $\left(R_{\text {net }}\right)$ change is very effective in $\mathrm{E} 1\left(-\frac{\Delta R_{\text {net }}}{\Delta L E_{\uparrow}}=0.9\right.$ in $\mathrm{E} 1$ vs. 0.5 in A1B). It is important to note that by only considering atmospheric water/energy balances, we are able to constrain and interpret the different behaviors of $\mathrm{PBr}$ in $\mathrm{E} 1$ and $\mathrm{A} 1 \mathrm{~B}$ during the second half of the 21C. Specifically, the above analysis implies that bifurcation of $\mathrm{Br}$ (Fig. 6c) is required in order to achieve the transition to the larger acceleration of the hydrological cycle in A1B compared to $\mathrm{E} 1$. The Br bifurcation appears related to the different GHG and aerosol forcing in E1 and A1B. This is consistent to Liepert and Previdi (2009), who interpret the different behavior of the $\mathrm{PBr}$ for aerosol-only and GHG-only experiments with a fully coupled GCM. They found that, for the GHG-only experiment, the sensible heat flux trends tend to be anti-correlated to the latent heat flux changes, whereas for the aerosol-only case sensible and latent heat flux trends display positive correlations. Interestingly, for both E1 and $\mathrm{A} 1 \mathrm{~B}$ the $\mathrm{PBr}$ over the ocean is always larger in absolute value compared to land. This suggests that the limited availability of water for land may play a role by favoring relatively more 
Table 3. Same as Table 2 but for contributions to rainfall coming from (left) atmospheric radiation, (middle) surface sensible heat flux and (right) atmospheric sensible-heat convergence.

\begin{tabular}{cccccccc}
\hline \multicolumn{7}{c}{$\begin{array}{c}\text { Contributions(\%) to Precipitation Change } \\
\text { from Atmospheric Energy Conservation }\end{array}$} \\
\hline & & \multicolumn{2}{c}{ Radiation } & Sensible Heat Surf. & Sensible Heat Conv \\
\cline { 3 - 9 } Climatology & Scenario & Land & Sea & Land & Sea & Land & Sea \\
\hline Mid-21C & E1 & 47.0 & 76.4 & 21.4 & 57.6 & 31.5 & -34.0 \\
$(2035-2065)$ & A1B & 28.4 & 48.1 & 36.2 & 92.1 & 35.3 & -38.9 \\
\hline End-21C & E1 & 52.7 & 78.3 & 17.6 & 52.5 & 29.6 & -30.8 \\
$(2070-2099)$ & A1B & 34.0 & 50.9 & 33.7 & 83.2 & 32.2 & -39.9 \\
\hline
\end{tabular}

sensible heat in the competition for flux partitioning at the surface (Sutton et al., 2007).

\section{Discussion and conclusions}

The mitigation scenario (E1) is effective in constraining global warming below $2 \mathrm{~K}$ compared to the 1950-2000 historical period and with a stabilization by the end-21C. On the contrary, the hydrological cycle in E1 does not follow temperature towards a stabilization path and continue to increase over the mitigation period. Quite unexpectedly, the mitigation scenario strengthen the hydrological cycle even more than SRES A1B till around 2070, thus displaying the difference between E1 and A1B of the relationship between temperature and precipitation.

Our analysis shows that in both scenarios the acceleration of the hydrological cycle over global land during the $21 \mathrm{C}$ is mainly sustained (E1: 67.4\% in mid-21C (2035-2065) and $63.8 \%$ in end-21C (2070-2100); A1B: $65.8 \%$ in mid-21C and $65.5 \%$ in end-21C) by the increased evapotranspiration over the continents and for about one third also by moisture convergence from oceans (E1: $32.6 \%$ in mid-21C and $36.2 \%$ in end-21C; A1B: $34.2 \%$ in mid-21C and $34.5 \%$ in end21C). On the other hand, moisture divergence reduces the precipitation increase over the ocean for both E1 $(-19.8 \%$ in mid-21C and $-21.6 \%$ in end-21C) and A1B (-23.9\% in mid-21C and $-25.8 \%$ in end-21C). We show that in the mid-21C climatology precipitation increases more in E1 than A1B over both land and sea mostly because of the larger increase in surface evaporation. A considerable contribution over land (about one third) also comes from the larger increase in moisture convergence from the oceans compared to A1B. Interestingly, similar contributions to the difference in precipitation change (about two thirds from evaporation and one third from moisture convergence) is observed for both mid- and end-21C climatologies, despite the fact that global precipitation increases more in A1B in the end-21C.

Through the application of the principle of conservation of energy in the atmosphere, we show that the larger strengthening of the hydrological cycle in E1 than A1B till around 2070 is mostly due to higher levels of radiative cooling (primarily reduced absorption of solar radiation) of the atmosphere in E1. This is consistent with the mechanism described in previous studies (Liepert et al., 2004; Feichter et al., 2004; Andrews et al., 2009) and appears to be a result, at least in part, of abated sulfate aerosol concentration compared to A1B. For the end-21C climatology, the difference in the projected change in solar and thermal radiation between $\mathrm{E} 1$ and A1B balance each other so that the net radiative contribution to differential change in precipitation is close to zero. On the other hand, it is the marked difference in surface-flux partitioning in the end-21C, with a considerably larger reduction in surface sensible heat flux towards atmosphere for A1B, that feeds the much larger acceleration of the hydrological cycle compared to E1 over both the land and ocean.

Hydrology acceleration leads to increased energy availability in the atmosphere due to latent-heat release during precipitation. The corresponding increase in surface latent heat flux would require a -1.0 value of the $\mathrm{PBr}$ if the only factor compensating for the latent-heat released in the atmosphere is the reduction of sensible heat from the surface. However, we show that other factors may contribute to compensate for the atmospheric energy enhancement due to hydrology acceleration, thus leading to less negative $\mathrm{PBr}$ values. These factors are the increase in atmospheric divergence of sensible heat, increase of atmospheric convergence of latent heat, and enhancement of atmospheric radiative cooling. In both mid-21C and end-21C and over both the land and ocean, we found that the changes in sensible and latent heat convergence terms balance very closely between each other so that they have no appreciable overall effect on $\mathrm{PBr}$. Apart from this common characteristic, our results show that baseline and mitigation scenarios behave very differently and two distinct mechanisms characterize the diverse strengthening of the hydrological cycle in mid- and end-21C. The increase of atmospheric radiative cooling, which always displays an absolute value of the ratio with latent-heat change larger than 0.5, dominates in E1 throughout mid- to end-21C. In the baseline scenario, radiative cooling is weakly effective, in part because of the unabated atmospheric aerosols there. 
This determines a drastic perturbation of surface flux partitioning in $\mathrm{A} 1 \mathrm{~B}$ with large negative $\mathrm{PBr}$ values during the second half of the 21C. It follows the marked bifurcation of the $\mathrm{Br}$ between $\mathrm{E} 1$ and $\mathrm{A} 1 \mathrm{~B}$, which ultimately induces the corresponding larger strengthening of the hydrological cycle in A1B during the last decades of the projected 21C. Consistent with Liepert and Previdi (2009), bifurcation of the Bowen ratio appears related to the different GHG and aerosol forcings in E1 and A1B. They showed that the forcing by GHGs tends to produce changes in sensible heat flux that are anticorrelated to the changes in latent heat flux. On the other hand, for the aerosol forcing case the sensible and latent heat flux trends show positive correlation.

The methodological approach proposed in this work has proven useful in improving our understanding of the contributions to the projected strengthening of the hydrological cycle and the different behaviors of the baseline and mitigation scenarios. More importantly, our study shows that mitigation policies that promote abatement of both anthropogenic GHGs and sulfate aerosols may obtain opposite effects on global temperature and precipitation, depending on the relative GHG and aerosol reductions. While they can obtain stabilization of global warming by the end-21C, we warn that the abatement of sulfate aerosols may lead to unexpectedly larger increases in global precipitation that may last for decades after global warming is effectively mitigated. A recent paper by van Oldenborgh et al. (2012) suggests that decadal climate predictions may have skill due to predictable components in the boundary conditions such as GHGs and atmospheric aerosols. Our results show that radiative forcing by sulfate aerosols may be particularly effective in perturbing global hydrological strength at the decadal time-scale. In particular, we show that the effect of aerosols may even overcome the underlying precipitation coupling with global warming, which on the other hand is mostly related to projected increase in GHGs. We suggest that predictable components of the radiative forcing by aerosols may have the potential to effectively contribute to the decadal-scale predictability of changes in the hydrological strength.

Acknowledgements. This work was supported by the ENSEMBLES project, funded by the European Commission's 6th Framework Program through contract GOCE-CT-2003-505539. M. Vichi and P. G. Fogli acknowledge the support of the Italian Ministry of Education, University and Research and the Ministry for Environment, Land and Sea through the project GEMINA. We are grateful to B. G. Liepert and the anonymous reviewer whose comments greatly improved the quality of the manuscript. Special thanks to C. Cagnazzo and I. Cionni for the useful scientific discussions and to M. Izumi for the English editing of the manuscript.

Edited by: V. Lucarini

\section{References}

Alessandri, A.: Effects of Land Surface and Vegetation Processes on the Climate Simulated by an Atmospheric General Circulation Model, PhD Thesis in Geophysics, Bologna University Alma Mater Studiorum, 114 pp., 2006.

Alessandri, A., Gualdi, S., Polcher, J., and Navarra, A.: Effects of Land Surface-Vegetation on the Boreal Summer Surface Climate of a GCM, J. Climate, 20, 255-277, 2007.

Andrews, T., Forster, P. M., and Gregory, J. M.: A surface energy perspective on climate change, J. Climate, 22, 2557-2570, doi:10.1175/2008JCLI2759.1, 2009.

Andrews, T., Forster, P. M., Boucher, O., and Bellouin, N.: Precipitation, radiative forcing and global temperature change, Geophys. Res. Lett., 37, L14701, doi:10.1029/2010GL043991, 2010.

Bouwman, L., Kram, T., and Klein-Goldewijk, K.: Integrated Modelling of Global Environmental Change. An Overview of IMAGE 2.4, Netherlands Environmental Assessment Agency, Bilthoven, 2006.

Boucher, O. and Pham, M.: History of sulfate aerosol radiative forcings, Geophys. Res. Lett., 29, 1308, doi:10.1029/2001GL014048, 2002.

Collatz, G. J., Berry, J. A., and Clark, J. S.: Effects of climate and atmospheric $\mathrm{CO}_{2}$ partial pressure on the global distribution of C-4 grasses: present, past, and future, OECOLOGIA, 114, 441454, 1998.

Douville, H., Salas-Melia, D., and Tyteca, S.: On the tropical origin of uncertainties in the global land precipitation response to global warming, Clim. Dynam., 26, 367-385, 2006.

Ducoudré, N., Laval, K., and Perrier, A.: SECHIBA, a New Set of Parameterizations of the Hydrologic Exchanges of the LandAtmosphere Interface within the LMD Atmospheric General Circulation Model, J. Climate, 6, 248-273, 1993.

Feichter, J., Roeckner, E., Lohmann, U., and Liepert, B.: Nonlinear aspects of the climate response to greenhouse gas and aerosol forcing, J. Climate, 17, 2384-2398, 2004.

Fogli, P. G., Manzini, E., Vichi, M., Alessandri, A., Gualdi, S., Scoccimarro, E., Masina, S., and Navarra, A.: INGV-CMCC Carbon: A Carbon Cycle Earth System Model, CMCC Tech. Rep. RP0061, http://www. cmcc.it/publications-meetings/publications/research-papers/ rp0061-ingv-cmcc-carbon-icc-a-carbon-cycle-earth-system-model (last access: June 2012), 2009.

Hibbard, K. A., Meehl, G. A., Cox, P. M., and Friedlingstein, P.: A strategy for climate change stabilization experiments, EOS Trans AGU, 88, 217-221, 2007.

Huntington, T. G.: Evidence for intensification of the global water cycle: review and synthesis, J. Hydrol., 319, 83-95, 2006.

Hartman, D. L.: Global Physical Climatology , International Geophysics Series, edited by: Dmowska, R. and Holton, J. R., Academic Press, 56, 411 pp., 1994.

Held, I. M. and Soden, B. J.: Robust responses of the hydrological cycle to global warming, J. Climate, 19, 5686-5699, 2006.

Johns, T. C., Royer, J.-F., Hoschei, I., Huebener, H., Roeckner, E., Manzini, E., May, W., Dufresne, J.-L., Ottera, O. H., van Vuuren, D. P., Salas y Melia, D., Giorgetta, M. A., Denvil, S., Yang, S., Fogli, P. G., Korper, J., Tjiputra, J. F., Stehfest, E., and Hewitt, C. D.: Climate change under aggressive mitigation: the ENSEMBLES multi-model experiment, Clim. Dynam., 37, 1975-2003, doi:10.1007/s00382-011-1005-5, 2011. 
Kiehl, J. T., Schneider, T. L., Portmann, R. W., and Solomon, S.: Climate forcing due to tropospheric and stratospheric ozone, J. Geophys. Res., 104, 31239-31254, 1999.

Lambert, F. H. and Webb, M. J.: Dependency of global mean precipitation on surface temperature, Geophys. Res. Lett., 35, L16706, doi:10.1029/2008GL034838, 2008.

Liepert, B. G., and Previdi, M.: Do models and observations disagree on the rainfall response to global warming?, J. Climate, 22, 3156-3166, 2009.

Liepert, B. G. and Previdi, M.: Inter-model variability and biases of the global water cycle in CMIP3 coupled climate models, Environ. Res. Lett., 7, 014006, doi:10.1088/1748-9326/7/1/014006, 2012

Liepert, B. G., Feichter, J., Lohmann, U., and Roeckner, E.: Can aerosols spin down the water cycle in a warmer and moister world?, Geophys. Res. Lett., 31, L06207, doi:10.1029/2003GL019060, 2004.

Lohmann, U. and Roeckner, E.: Design and performance of a new cloud microphysics scheme developed for the ECHAM4 general circulation model, Clim. Dynam., 12, 557-572, 1996.

Lucarini, V. and Ragone, F.: Energetics of Climate Models: Net Energy Balance and Meridional Enthalpy Transports, Rev. Geophys., 49, RG101, doi:10.1029/2009RG000323, 2011.

Lucarini, V., Danihlik, R., Kriegerova, I., and Speranza, A.: Hydrological cycle in the Danube basin in present-day and XXII century simulations by IPCCAR4 global climate models, J. Geophys. Res., 113, D09107, doi:10.1029/2007JD009167, 2008.

Madec, G., Delecluse, P., Imbard, M., and Levy, C.: OPA version 8.1 Ocean General Circulation Model reference manual, Technical report, LODYC/IPSL Note 11, 1998.

Mariotti, A., Struglia, M. V., Zeng, N., and Lau, K.-M.: The Hydrological Cycle in the Mediterranean Region and Implications for the Water Budget of the Mediterranean Sea, J. Climate, 15, 1674-1690, 2001.

Nakicenovic, N. and Swart, R. (Eds.): Special Report on Emissions Scenarios. A Special Report of Working Group III of the Intergovernmental Panel on Climate Change, 728 pp., Cambridge University Press, Cambridge, UK, ISBN 0521804930, 2000.

Peixoto, J. P. and Oort, A. H.: Physics of climate; American Institute of Physics (AIP), New York, 1992.

Polcher, J., McAvaney, B., Viterbo, P., Gaertner, M.-A., Hahmann, A., Mahfouf, J.-F., Noilhan, J., Phillips, T., Pitman, A., Schlosser, C. A., Schulz, J.-P., Timbal, B., Verseghy, D., and Xue, Y.: A proposal for a general interface between land-surface schemes and general circulation models, Global Planet. Change, 19, 261$276,1998$.

Roeckner, E., Bauml, G., Bonaventura, L., Brokopf, R., Esch, M., Giorgetta, M., Hagemann, S., Kirchner, I., Kornblueh, L., Manzini, E., Rhodin, A., Schlese, U., Schulzweida, U., and Tompkins, A.: The atmospheric general circulation model ECHAM5. Part I: Model description. Rep. No. 349, Max-PlanckInstitut für Meteorologie, Hamburg, Germany, 127 pp., 2003.

Sutton, R. T., Dong, B., and Gregory, J. M.: Land/sea warming ratio in response to climate change: IPCC AR4 model results and comparison with observations, Geophys. Res. Lett., 34, L02701, doi:10.1029/2006GL028164, 2007.
Tanre, D., Geleyn, J., and Slingo, J.: First results of the introduction of an advanced aerosol-radiation interaction in ECMWF low resolution global model, in Aerosols and Their Climatic Effects, edited by: Gerber, H. and Deepak, A., 133-177, A. Deepak, Hampton, Va, 1984

Timmermann, R., Goosse, H., Madec, G., Fichefet, T., Etheb, C. and Duliere, V.: On the representation of high latitude processes in the ORCA-LIM global coupled sea ice ocean model, Ocean Modell., 8, 175-201, 2005.

Trenberth, K. E.: Changes in precipitation with climate change, Clim. Res., 47, 123-138, doi:10.3354/cr00953, 2011.

Trenberth, K. E. and Shea, D. J.: Relationship between precipitation and surface temperature, Geophys. Res. Lett., 32, L14703, doi:10.1029/2005GL022760, 2005

Trenberth, K. E., Caron, J. M., and Stepaniak, D. P.: The atmospheric energy budget and implications for surface fluxes and ocean heat transports, Clim. Dynam., 17, 259-276, 2001.

Trenberth, K. E., Jones, P. D., Ambenje, P., Bojariu, R., Easterling, D., Klein Tank, A., Parker, D., Rahimzadeh, F., Renwick, J. A., Rusticucci, M., Soden, B., and Zhai, P.: Observations: Surface and Atmospheric Climate Changen in: Climate Change 2007: The Physical Science Basis. Contribution of Working Group I to the Fourth Assessment Report of the Intergovernmental Panel on Climate Change, edited by: Solomon, S., Qin, D., Manning, M., Chen, Z., Marquis, M., Averyt, K. B., Tignor, M., and Miller, H. L., Cambridge University Press, Cambridge, United Kingdom and New York, NY, USA, 2007.

Valcke, S.: OASIS3 User Guide (prism_2-5), PRISM Report No 2, 6th Edn., CERFACS, Toulouse, France, 64 pp., 2006.

van Oldenborgh, G. J., Doblas-Reyes, F.-J., Wouters, B., Hazeleger, and W.: Decadal prediction skill in a multi-model ensemble, Clim. Dynam., 38, 7-8, 1263-1280, doi:10.1007/s00382-0121313-4, 2012.

van Vuuren, D., den Elzen, M., Lucas, P., Eickhout, B., Strengers, B. van Ruijven, B., Wonink, S., and van Houdt, R.: Stabilizing greenhouse gas concentrations at low levels: an assessment of reduction strategies and costs, Clim. Change, 81, 119-159, doi:10.1007/s10584-006-9172-9, 2007.

Vichi, M., Pinardi, N., and Masina, S.: A generalized model of pelagic biogeochemistry for the global ocean ecosystem. Part I: theory, J. Mar. Sys., 64, 89-109, 2007a.

Vichi, M., Masina, S., and Navarra, A.: A generalized model of pelagic biogeochemistry for the global ocean ecosystem. Part II: numerical simulations, J. Mar. Sys., 801, 110-134, 2007b.

Vichi, M., Manzini, E., Fogli, P. G., Alessandri, A., Patara, L., Scoccimarro, E., Masina, S., and Navarra, A.: Global and regional ocean carbon uptake and climate change: Sensitivity to an aggressive mitigation scenario, Clim. Dynam., 37, 1929-1947, doi:10.1007/s00382-011-1079-0, 2011.

Wentz, F. J., Ricciardulli, L., Hilburn, K. A., and Mears, C. A.: How Much More Rain Will Global Warming Bring?, Science, 317, 233-235, 2007.

Zeng, N., Mariotti, A., and Wetzel, P.: Terrestrial Mechanisms of Interannual $\mathrm{CO}_{2}$ Variability, Global Biogeochem. Cy., 19, 25392558, 2004. 